\title{
Assessment of reversibility of airway obstruction in patients with chronic obstructive airways disease
}

\author{
M Nisar, M Walshaw, J E Earis, M G Pearson, P M A Calverley
}

\section{Abstract}

Spirometry before and after an inhaled beta agonist or a course of oral prednisolone is widely used to detect reversible airflow limitation in patients with chronic obstructive lung disease. How many of these patients have a response and how the response to beta agonists relates to the response to corticosteroids is not clear. In 127 outpatients (mean (SD) FEV $_{1} 0.92(0.38)$ 1) who had a clinical diagnosis of chronic obstructive lung disease (continuous breathlessness for more than six months and an $\mathrm{FEV}_{1} /$ forced vital capacity (FVC) ratio $<60 \%$ ) and who appeared to be stable, the change in FEV 1 was measured after salbutamol $200 \mu \mathrm{g}$ from a metered dose inhaler and $5 \mathrm{mg}$ from a nebuliser. Symptoms and spirometric values were recorded before and after two weeks of oral prednisolone $30 \mathrm{mg}$. Reversibility was defined as a response in $F E V_{1}$ of $15 \%$ or more from baseline alone and as a $15 \%$ change and a minimum increase of at least $200 \mathrm{ml}$. The latter gave results that showed greater internal consistency between the drug regimens. On the basis of this criterion 56 patients $(44 \%)$ had no response to salbutamol or prednisolone, 71 responded to salbutamol (including all 27 steroid responders), and 25 patients had a response to salbutamol $5 \mathrm{mg}$ but not to $200 \mu \mathrm{g}$. In general, the largest increase in FEV $_{1}$ after salbutamol occurred in the subjects with greatest improvement after prednisolone. Subjects showing a response in $\mathrm{FEV}_{1}$ after two weeks' prednisolone had a fall in total symptom score, unlike those who had no response to any treatment or a response to salbutamol only. These data show that reversibility in response to beta agonists is common in patients diagnosed on clinical grounds as having stable chronic obstructive lung disease, that it can be substantial, and that it is best detected by using a larger dose of salbutamol. Salbutamol responders were those most likely to improve after a trial of oral prednisolone. Allowance should be made for the variability of $\mathrm{FEV}_{1}$ in the calculation of the percentage response at low baseline values (less than 1 litre).

Chronic obstructive pulmonary disease is one of the commonest clinical problems presenting to the chest physician but there is a shortage of firm data on which to base rational diagnosis and management. Airflow limitation is improved in many patients by bronchodilator drugs $^{12}$ and less frequently by oral corticosteroids. ${ }^{34}$ Some physicians test for reversibility of airflow obstruction by measuring $\mathrm{FEV}_{1}$ before and after $200 \mu \mathrm{g}$ salbutamol; others strongly advocate a trial of oral corticosteroids for all patients diagnosed as having chronic obstructive lung disease. There is similar uncertainty about the appropriateness of defining reversibility as an increase in $\mathrm{FEV}_{1}$ after treatment, particularly in patients with a low $\mathrm{FEV}_{1} .^{56}$

We have tried to resolve some of this uncertainty by studying a consecutive series of stable outpatients diagnosed as having chronic obstructive lung disease and presenting to a single hospital. We addressed the following questions: (1) How often do such patients have an $F_{1} V_{1}$ response to inhaled salbutamol and how does the response to $200 \mu \mathrm{g}$ compare with the response to $5 \mathrm{mg}$ ? (2) Do the same patients respond to corticosteroids and salbutamol? (3) Are the spirometric changes related to symptomatic improvement?

\section{Methods}

All outpatients referred with a history of progressive continuous breathlessness of more than six months' duration and with spirometric evidence of limitation $\left(\mathrm{FEV}_{1} /\right.$ forced vital capacity (FVC) $<60 \%$ ) were considered for the study. Patients were excluded if they had had a recent exacerbation of a chest illness or had any coexisting cardiovascular or lung disorder. Patients with previously documented asthma and patients taking oral corticosteroids were also excluded.

We assessed 127 consecutive patients who met the above criteria. The 78 patients taking bronchodilators and the 43 taking oral theophylline were asked to stop the drugs for at least six hours and for 24 hours respectively before the tests. All patients gave their informed consent to the study protocol, which formalised our existing clinical practice. All the spirometric measurements were made with a wet spirometer (PK Morgan). In each case the best $\mathrm{FEV}_{1}$ and FVC from three tracings were recorded.

On the first visit patients completed a respiratory questionnaire that included questions on the presence or absence of wheeze, cough, sputum, and dyspnoea. Clinical stability was confirmed. Patients then performed baseline 
Figure 1 Venn diagram to show the distribution of responders among the three test modalities:

(a) criterion $1:$ increase in $F E V_{1}$ of $\geqslant 15 \%$; (b) criterion $2:$ increase in $F E V_{1}$ of $\geqslant 15 \%$ and $\geqslant$ $200 \mathrm{ml}$. (a)

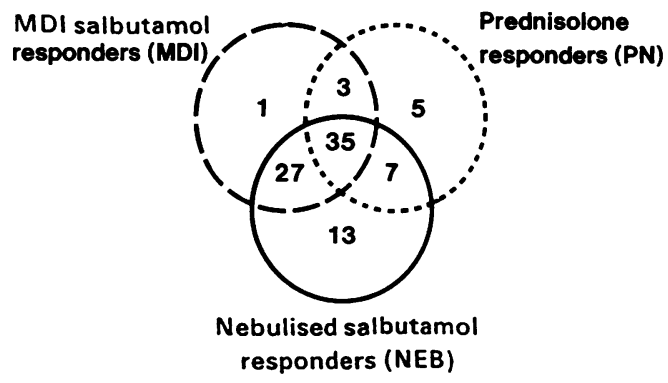

(b)

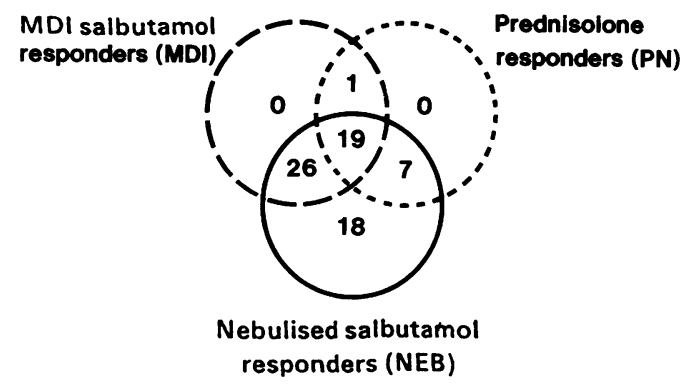

spirometric tests, and after being shown how to use a placebo metered dose inhaler they inhaled two puffs of salbutamol (200 $\mu \mathrm{g}$ total) one minute apart under supervision. Spirometry was repeated at 15 minutes. The patients then inhaled $5 \mathrm{mg}$ salbutamol via a System 22 nebuliser $(5 \mathrm{l} / \mathrm{min})$ and spirometry was repeated after a further 15 minutes. Lastly, each patient was prescribed oral prednisolone $30 \mathrm{mg}$ daily for two weeks. Spirometry was repeated and the respiratory questionnaires administered at the end of the two weeks. The response to each treatment was assessed by comparing the postbronichodilator $\mathrm{FEV}_{1}$ with the baseline value.

We examined two separate criteria for deciding if a response was greater than that expected by the random variation of the measurement: criterion 1: a rise in $\mathrm{FEV}_{1}$ of at least $15 \%$ from the baseline value; criterion 2: a rise in $\mathrm{FEV}_{1}$ of at least $15 \%$ from the baseline value in addition to an absolute increase in $\mathrm{FEV}_{1}$ of at least $200 \mathrm{ml}$ (to exclude errors due to the known coefficient of variation of spirometry ${ }^{67}$ ).

Data are expressed as means with standard variations in parentheses and comparisons within groups were made by Student's unpaired $t$ test.

\section{Results}

Of the 127 patients, $81\left(64^{\circ}{ }_{\mathrm{o}}\right)$ were male and $118\left(93^{\circ}{ }_{0}\right)$ were cigarette smokers (mean 36 pack years). Forty four $\left(35^{\circ} \%\right)$ were current smokers. Ninety nine $\left(78^{\circ}{ }_{0}\right)$ gave a history of regular cough and sputum production. Mean $\mathrm{FEV}_{1}$ was $0.92(0.38) 1\left(43^{\circ}{ }_{\mathrm{o}}\right.$ of predicted $)$ and mean FVC $2.13(0.73) 1$. Almost two thirds $\left(63^{\circ}{ }_{0}\right)$ of the patients had an $\mathrm{FEV}_{1}$ of less than 1 litre.

On the basis of criterion 1,91 patients $(72 \%)$ responded to one or more of the three treatments but the distribution of reponses between treatments showed no clear pattern (fig 1a). Fifty patients responded to prednisolone, of whom five had no response to either form of salbutamol. Among the salbutamol responders four patients responded to $200 \mu \mathrm{g}$ but not to $5 \mathrm{mg}$. Such "unexpected" results were always associated with small absolute volume changes.

When criterion 2 was applied a different and simpler pattern emerged (fig $1 b$ ). Seventy one patients were responders but only one of these responded to $200 \mu \mathrm{g}$ salbutamol by metered dose inhaler and not to $5 \mathrm{mg}$ by nebuliser. This patient showed a fall of 0.31 in $\mathrm{FEV}_{1}$ after nebulised salbutamol. All the subjects who responded to oral prednisolone showed a response to inhaled salbutamol $200 \mu \mathrm{g}$ or $5 \mathrm{mg}$. The response to salbutamol $200 \mu \mathrm{g}$ by metered dose inhaler identified only 46 responders. The

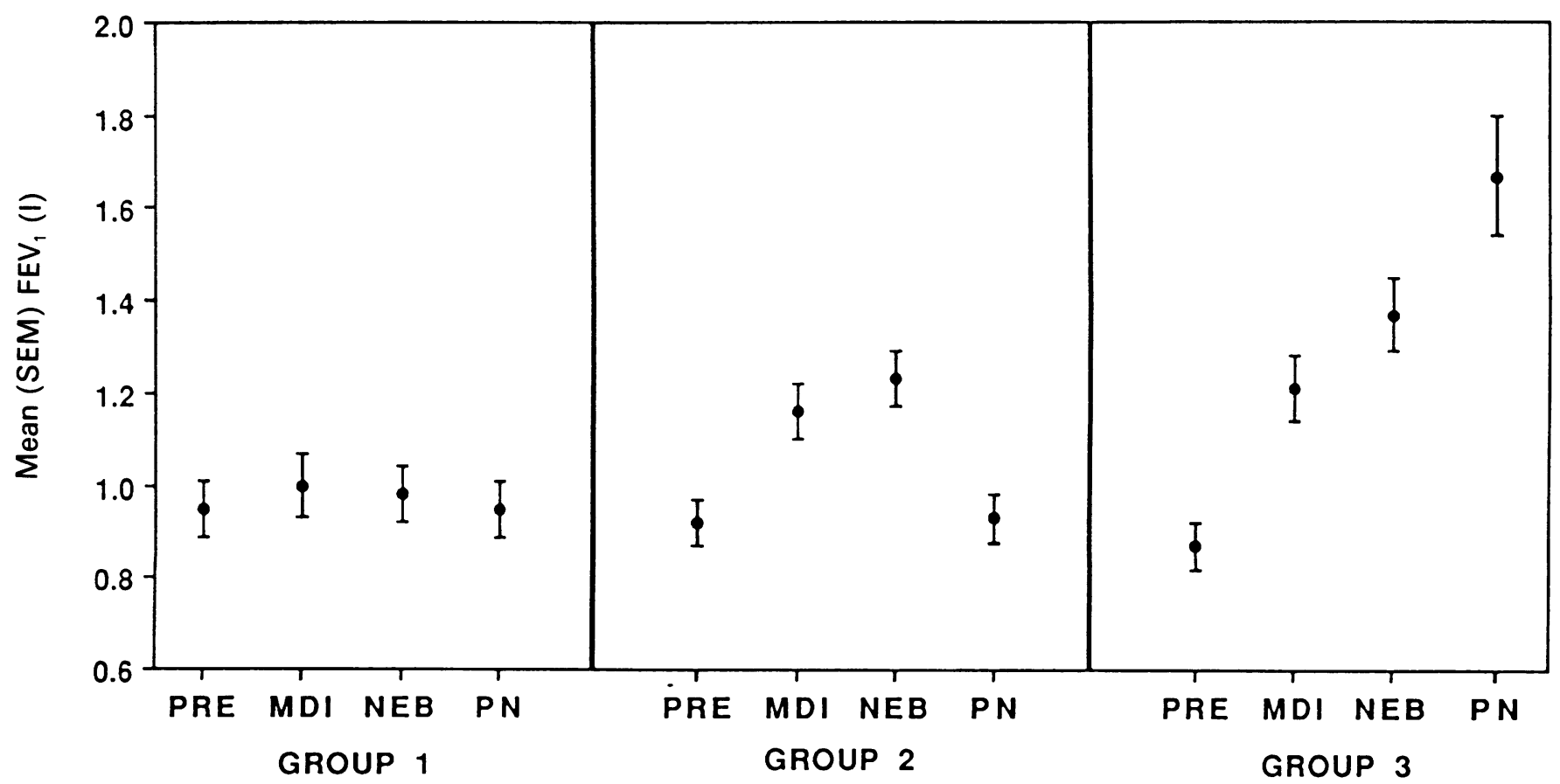

Figure 2 Mean (SEM) FEV, (l) before and after salbutamol (MDI-200 $\mu \mathrm{g}$ by metered dose inhaler; NEB-5 mg by nebuliser) and oral prednisolone ( $P N-30 \mathrm{mg}$ daily for two weeks) in the three groups. 
Table 1 Clinical characteristics, eosinophil count, and spirometric values of the three groups ${ }^{\star}$ of patients

\begin{tabular}{|c|c|c|c|}
\hline & $\begin{array}{l}\text { Group 1 } \\
(n=56)\end{array}$ & $\begin{array}{l}\text { Group } 2 \\
(n=44)\end{array}$ & $\begin{array}{l}\text { Group } 3 \\
(n=27)\end{array}$ \\
\hline 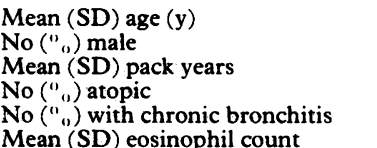 & $\begin{array}{l}61 \cdot 5(8 \cdot 1) \\
31(55) \\
37(25) \\
19(34) \\
36(64)\end{array}$ & $\begin{array}{l}59 \cdot 8(8 \cdot 0) \\
30(68) \\
36(26) \\
13(30) \\
28(64)\end{array}$ & $\begin{array}{c}62 \cdot 5(7 \cdot 5) \\
20(74) \\
31(22) \\
11(41) \\
17(63)\end{array}$ \\
\hline $\begin{array}{l}\left(\times 10^{-6}\right) \\
\text { Mean (SD) baseline } \mathrm{FEV}_{1}(\mathrm{l}) \\
\text { Mean (SD) baseline (1) forced vital }\end{array}$ & $\begin{array}{l}134(153) \\
0.95(0.46)\end{array}$ & $\begin{array}{l}190(264) \\
0.92(0.35)\end{array}$ & $\begin{array}{l}451(486) \\
0.87(0.25)\end{array}$ \\
\hline capacity & $2.02(0.76)$ & $2.28(0.78)$ & $2.09(0.56)$ \\
\hline
\end{tabular}

«See under "Methods."

addition of a steroid trial would have identified a further seven responders, whereas the use of nebulised salbutamol caused a further 25 patients to be detected.

On the basis of criterion 2 (fig $1 b$ ), the patients' responses can be divided into three groups. The first group (group 1) comprises 56 patients who failed to respond to any treatment. Group 2 includes 44 patients who responed only to beta agonists. Group 3 contains 27 patients who responded to both beta agonists and oral prednisolone. There was no difference in mean age, sex, smoking habits, or baseline $\mathrm{FEV}_{1}$ values between the three groups; the eosinophil count was significantly higher in subjects in group 3 ( $p<0.001$; table 1$)$. Figure 2 shows the mean change in FEV 1 with the three treatments for the three groups. In group 1 the mean changes in $\mathrm{FEV}_{1}$ were close to zero for each treatment and the standard deviation was $160 \mathrm{ml}$. As mean $\mathrm{FEV}_{1}$ was unchanged the standard deviation is a measure of the reproducibility of the $\mathrm{FEV}_{1}$ in these patients. In groups 2 and 3 nebulised salbutamol $5 \mathrm{mg}$ produced a greater increase in $\mathrm{FEV}_{1}$ than did $200 \mu \mathrm{g}$ salbutamol administered by metered dose inhaler $(p<0.05)$. In group 2 despite substantial increases in $\mathrm{FEV}_{1}$ after salbutamol (up to $0.6 \mathrm{l}$ ) there was not even a trend towards an increase in baseline $\mathrm{FEV}_{1}$ after two weeks of oral prednisolone. Group 3 patients showed larger changes in $\mathrm{FEV}_{1}$ after both doses of salbutamol than patients in group $2(p<0.01)$ and the increase after prednisolone was even greater. The substantial increase in $\mathrm{FEV}_{1}$ in group 3 is partly due to three subjects whose $\mathrm{FEV}_{1}$ improved by more than 1 litre. These three subjects could not be separated from either of the other two groups on the basis of symptoms or initial lung function. Although the response to steroids was broadly related to that after nebulised salbutamol (fig 3), the scatter of the data is too large for the magnitude of one to be predicted from a knowledge of the other.

The percentage of patients with particular symptoms and the mean breathlessness score and FEV 1 before and after the steroid trial for the three groups are shown in table 2 . There was no improvement in symptoms after the steroid trial for patients in groups 1 and 2 who also had no change in $\mathrm{FEV}_{1}$; and group 3 patients had less cough, sputum, wheeze, and breathlessness after treatment in conjunction with the improvement in $\mathrm{FEV}_{1}$.

\section{Discussion}

With the recognition that the degree of airflow limitation rather than symptoms of chronic bronchitis is the important factor in determining outcome in patients with chronic obstructive lung disease, ${ }^{8}$ more attention is being paid to the detection and improvement of airflow limitation. The definition of chronic obstructive lung disease adopted in this study is a clinical one that can be readily applied in any chest clinic. The requirement for a history of persistent progressive breathlessness excludes patients with classical asthma and the reduced $F_{1} / F V C$ ratio ensures that airflow obstruction is present. We excluded patients with other cardiorespiratory conditions in order not to confuse the data. The tests of reversibility were chosen to represent those commonly used in clinical practice in the United Kingdom.

The American Thoracic Society recommends that a $15 \%$ increase in $\mathrm{FEV}_{1}$ above baseline (criterion 1) should be considered as a positive response to a bronchodilator ${ }^{5}$ and this definition is widely used in pharmaceutical trials. Many patients with chronic obstructive
Figure 3 Change in $F E V_{1}(l)$ in response to oral prednisolone and nebulised salbutamol in patients responding to both agents.

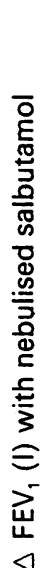

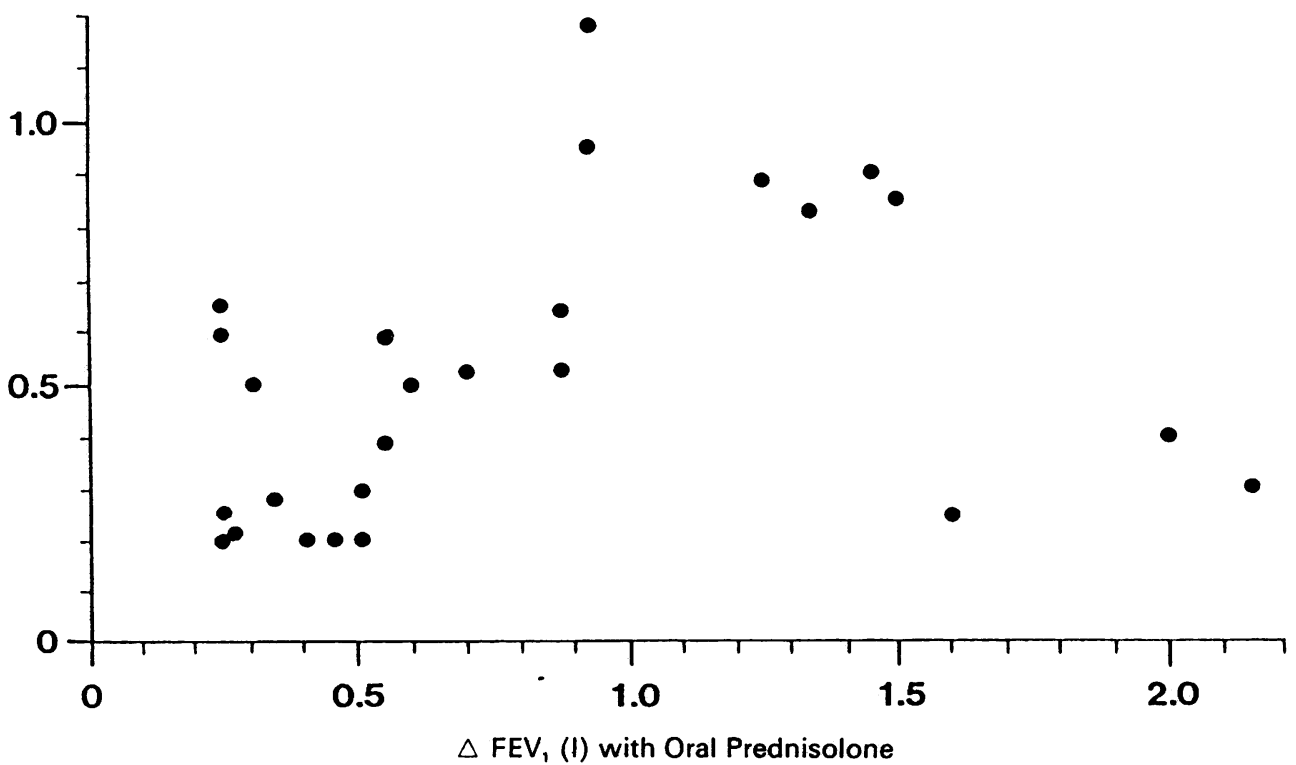


Table 2 Symptoms and spirometric values before and after prednisolone in the three groups ${ }^{\star}$ of patients

\begin{tabular}{|c|c|c|c|c|c|c|}
\hline & \multicolumn{2}{|l|}{$\begin{array}{l}\text { Group 1 } \\
(n=56)\end{array}$} & \multicolumn{2}{|l|}{$\begin{array}{l}\text { Group 2 } \\
(n=44)\end{array}$} & \multicolumn{2}{|l|}{$\begin{array}{l}\text { Group } 3 \\
(n=27)\end{array}$} \\
\hline & Before & After & Before & After & Before & After \\
\hline $\begin{array}{l}\text { No ( }\left(_{0}^{0}\right) \text { with: } \\
\text { cough }\left({ }^{\circ}{ }_{0}\right) \\
\text { wheeze }\left({ }^{\circ}{ }_{0}\right) \\
\text { sputum }\left({ }^{0}{ }_{0}\right)\end{array}$ & $\begin{array}{l}42(75) \\
46(82) \\
39(70)\end{array}$ & $\begin{array}{l}31(56) \\
34(60) \\
31(56)\end{array}$ & $\begin{array}{l}33(75) \\
35(80) \\
36(82)\end{array}$ & $\begin{array}{l}30(68) \\
34(77) \\
30(69)\end{array}$ & $\begin{array}{l}22(81) \\
25(93) \\
24(89)\end{array}$ & $\begin{array}{l}14(52)^{\star \star} \\
15(56)^{\star \star} \\
13(48)^{\star \star}\end{array}$ \\
\hline Mean (SD) dyspnoea score* & $3.5(1.3)$ & $3 \cdot 1(1 \cdot 5)$ & $3 \cdot 7(1 \cdot 3)$ & $3 \cdot 3(1 \cdot 3)$ & $3.7(1.3)$ & $2 \cdot 7(1.4)^{\star \star}$ \\
\hline Mean (SD) $\mathrm{FEV}_{1}$ (1) & $0.95(0.45)$ & $0.95(0.45)$ & $0.92(0.35)$ & $0.93(0.34)$ & $0.87(0 \cdot 25)$ & $1.67(0.67)^{\star \star}$ \\
\hline
\end{tabular}

^See under "Methods."

$\star \star p<0.01$.

lung disease, however, have an $\mathrm{FEV}_{1}$ of a litre or less; a $15 \%$ change in $\mathrm{FEV}_{1}$ is then less than the coefficient of reproducibility of $\mathrm{FEV}_{1}$ measurement as shown by Tweedale and $\mathrm{McHardy}^{67}$ and confirmed in our data for patients of group 1 . When criterion 1 was used to determine whether the patient had had a response to treatment $70 \%$ of the patients were identified as responders. It is difficult to understand, however, why some patients should respond to $200 \mu \mathrm{g}$ salbutamol but not to $5 \mathrm{mg}$. If these inconsistent results were due to poor reproducibility of measurements in patients with a low $\mathrm{FEV}_{1}$, the addition of an absolute volume criterion would be expected to reduce such anomalies. Our data show that adopting criterion 2 did exactly that. Twenty of the patients with low volume changes were then labelled as non-responders and three clear response patterns emerged: no response, response to nebulised bronchodilator but not prednisolone, and response to both nebulised salbutamol and prednisolone. With this definition of responder only one patient showed an inconsistent response. He was the only patient in whom the $\mathrm{FEV}_{1}$ fell (by 0.3 litre) after nebulised salbutamol, which suggests that he might have had a bronchoconstrictor response to the preservative in the nebuliser solution (he has not been rechallenged).

The choice of the absolute volume to be used in criterion 2 is clearly arbitrary but ours has the advantage of simplicity and, moreover, does exceed the coefficient of reproducibility of the FEV measurement that has been reported. ${ }^{16}$ If criterion 2 were too harsh, then the non-responding patients (group 1) should show a trend towards a positive response. This did not occur for either FEV $\mathrm{F}_{1}$ or symptoms after the trial of prednisolone and thus provides indirect evidence for the appropriateness of this response criterion. Moreover, the only group to show significant improvement in symptoms after oral prednisolone was the one in which the spirometric improvement met our criterion 2 (table 2 ).

Giving $200 \mu \mathrm{g}$ salbutamol via a metered dose inhaler produced smaller increments in FEV, in fewer patients than nebulised salbutamol ( 5 mg) despite carefully supervised administration of the dose. Use of this dose would have missed $35 \%$ of patients identified as responders with the higher dose by nebuliser and also some patients who were later shown to be steroid responsive. Nebulisers are now widely available and circumvent the problem of poor compliance with treatment by metered dose inhaler. ${ }^{9}$ Moreover, a single $5 \mathrm{mg}$ dose of salbutamol is safe and using this dose for reversibility testing seems logical.

The role of the steroid trial has been extensively studied ${ }^{3410}$ but there is disagreement about the dose and the test to be used, ${ }^{10}$ and even whether it is relevant. ${ }^{11}$ Prednisolone 30 mg daily, as used in this study, is in the mid range of prednisolone doses used previously. The $21^{\circ}{ }_{0}$ of patients identified as steroid responders on the basis of criterion 2 is similar to the percentage found in previous studies ${ }^{12}$; there are data that support the claim that increasing either the dose $\mathrm{e}^{10}$ or the length of a steroid trial will increase the number of responders. Among the steroid non-responders, however, there was not even a trend towards a response by two weeks. This makes it unlikely that the numbers would have changed substantially had different steroid regimens been adopted.

The failure of $200 \mu \mathrm{g}$ salbutamol to detect a response in seven of the 27 patients who subsequently responded to steroids has provided the rationale for empirical trials of steroids in all patients with chronic obstructive lung disease. Our observation that $96 \%$ of the steroid responders had a response to nebulised salbutamol may make it possible to reduce the number of steroid trials with a negative outcome.

The use of change in $\mathrm{FEV}_{1}$ to assess the response to two weeks' oral prednisolone is supported by the clear symptomatic improvements that occurred in steroid responders, in contrast to the lack of any change in symptoms in non-responders. $\mathrm{FEV}_{1}$ changes appear therefore to reflect variables important to the patient. The addition of a minimum absolute volume criterion helped to clarify an otherwise confusing scatter of data.

The existence of patients not responsive to steroids who nevertheless show bronchodilatation with beta agonists has received little attention. They formed $30 \%$ of the study population and included 10 patients who had a greater than 0.4 litre increase in $F E V_{1}$. Whether the mechanism underlying airways obstruction in these patients is different cannot be answered here. Possibly steroid responders have an "asthmatic" component that is responding to the relief of airways inflammation, whereas those who respond only to bronchodilators are benefiting from the removal of resting bronchomotor tone. 
The use of the term reversibility of airways obstruction is fraught with difficulty. In common usage it implies a complete abolition of the physiological impairment seen in asthmatic patients. It is also used, however, to signify an improvement in pulmonary function greater than could be predicted by the random variation of the measurement. Our data show that reversibility in the second sense occurs frequently in patients with moderate to severe airflow limitation, at least with acute testing. By including a simple volume criterion to recognise the limitations of the measurement anomalous results can be avoided. High dose nebulised beta agonists can identify a subgroup who are more likely to respond to prednisolone and who have the greatest responses in absolute terms. The relation between short term responses and subsequent symptomatic and physiological progress with long term treatment is unknown. Whether testing during a single visit to the laboratory is reliable enough to help determine appropriate long term treatment has yet to be determined.
1 Anthonisen NR, Wright EC and the IPPB trial group. Bronchodilator response in chronic obstructive pulmonary disease. Am Rev Respir Dis 1986;133:814-9.

2 Anonymous. Airflow limitation-reversible or irreversible? Lancet 1988;i:26-7.

3 Mitchell DM, Gildeh P, Rehahn M, Dimond AH, Collins JV. Effects of prednisolone in chronic airflow limitation. Lancet 1984;ii:193-5.

4 Mendella LA, Manfreda J, Warren CPW, Anthonisen NR. Steroid response in stable chronic obstructive pulmonary Steroid response in stable chronic obstructi

5 American Thoracic Society. ATS Statement-Snowbird workshop on standardisation of spirometry. Am Rev Respir Dis 1979;119:831-8.

6 Tweedale PM, Alexander F, McHardy GJR. Short-term variability in FEV, and bronchodilator responsiveness in patients with obstructive ventilatory defects. Thorax 1987;43:487-90.

7 Gunawardena KA, Bouston K, Smith AP. Evaluation of the turbine pocket spirometer. Thorax 1987;43:689-93.

8 Fletcher C, Peto R, Tinker C, Speizer FE. The natural history of chronic bronchitis and emphysema. Oxford: history of chronic bronchitis and
Oxford University Press, 1976.

9 Patterson IC, Crompton GK. Use of pressurised aerosols by asthmatic patients. $\mathrm{Br}$ Med $J 1976 ; \mathrm{i}: 76-9$.

10 O'Reilly JF, Shaylor JM, Frominger KM, Harrison BDW. The use of the 12 minute walking rest in assessing the effect of oral steroid therapy in patients with chronic airways obstruction. Br J Dis Chest 1982;76:374-82.

11 Whyte KF, Flenley DC. Improving airflow limitation in chronic bronchitis and emphysema. In: Recent advances in respiratory medicine. London: Churchill Livingstone, 1985:203-9.

12 Eliasson O, Hoffman J, Trueb D, Frederick D, McCormick JR. Corticosteroids in COPD. Chest 1986;89:484-90. 